\title{
N $94-16034$
}

Scaling, Soil Moisture and Evapotranspiration in Runoff Models

\author{
Eric F. Wood
}

\author{
Water Resources Program \\ Princeton University \\ Princeton, NJ 08544
}

Accepted:

Special Issue on Hydroclimatology

Advances in Water Resources

October, 1993 
Abstract.

The effects of small-scale heterogeneity in land surface characteristics on the large-scale fluxes of water and energy in the land-atmosphere system has become a central focus of many of the climatology research experiments. The acquisition of high resolution land surface data through remote sensing and intensive land-climatology field experiments (like HAPEX and FIFE) has provided data to investigate the interactions between microscale land-atmosphere interactions and macroscale models. One essential research question is how to account for the small scale heterogeneities and whether 'effective' parameters can be used in the macroscale models. To address this question of scaling, the probability distribution for evaporation is derived which illustrates the conditions for which scaling should work. An correction algorithm that may appropriate for athe land parameterization of a GCM is derived using a 2nd order linearization scheme. The performance of the algorithm is evaluated. 
Introduction.

Research into land-atmospheric interactions suggest a strong coupling between land surface hydrologic processes and climate (Charney et al.. 1977; Walker and Rowntree, 1977; Shukla and Mintz, 1982; and Sud et al..1990.) Due to this coupling. the issue of 'scale interaction' for land surface-atmospheric processes has emerged as one of the critical unresolved problems for the parameterization of climate models. To help resolve this issue, the understanding of the scaling properties of water and energy fluxes with their corresponding storage terms (especially soil moisture) has been an important scientific objective of land-climatology experiments like FIFE (see Sellers etal. 1988) and GCIP (see WCRP, 1992).

In fact, the acquisition of high resolution land surface data through remote sensing and intensive land-climatology fleld experiments (like HAPEX and FIFE) has provided data to investigate the interactions between microscale land-atmosphere interactions and macroscale models. One essential research question is how to account for the small scale heterogeneities and whether 'effective' parameters can be used in the macroscale models. The current scientific thinking on this issue is mixed. For example Sellers et al. (1992) claim that analysis of the FIFE data supports that land-atmospheric models are almost scale invariant, a conclusion also reached by Nollhan (personal communication) using HAPEX-MOBILHY data. Counter arguments have been made by Avissar and Pielke (1989) who found that heterogenefty in land characteristics resulted in sea-breeze like circulations, and significant differences in surface temperatures and energy fluxes across the patches. The results of analyses presented later in this paper suggest that soil moisture is the critical varlable that controls the 
non-linear behaviour of land-atmospheric interactions, and the effect is most pronounced when soil moisture heterogeneity is such that part of the domain is under soil-vegetation control and part is under atmospheric control.

The understanding of the scale problem is critical for new climate projects such as the Global Energy and Water Experiment (GEWEX) or the Earth Observing System (Eos). It is also important for the parameterization of the macroscale land-surface hydrology in climate models, and crucial in our understanding in how to represent sub-grid variability in such macroscale models.

From a modeling perspective, it's important to establish the relationship between spatial variability in the inputs and model parameters. the scale being modeled and the proper representation of the hydrologic processes at that scale. Figure 1 presents a schematic for modeling over a range of scales. Let us consider this figure in light of the terrestrial water balance, which for a control volume may be written as:

$$
\left\langle\frac{\partial S}{\partial t}\right\rangle=\langle P\rangle-\langle E\rangle-\langle Q\rangle
$$

where $S$ represents the moisture in the soll column. E evaporation from the land surface into the atmosphere, $P$ the precipltation from the atmosphere to the land surface, and $Q$ the net runoff from the control volume. The spatial average for the control volume is noted by $\langle\cdot\rangle$.

Equation (1) is valid over all scales and only through the parameterization of individual terms does the water balance equation become a 'distributed' or 'lumped' model. By 'distributed' model, we mean a model which accounts for spatial varlability in inputs, processes or parameters. 
Lumped Versus Distributed Models.

Figure 1 presented a framework for considering the relationship between distributed and lumped models. Wood et al. (1988). Wood et al. (1990). Wood and Lakshmi (1993) studied the behaviour of aggregated inputs and the resulting hydrologic responses which lead to the concept of the representative elementary area, a scale where a statistical representation can replace actual patterns of varlability. In this paper we compare the output between a macroscale. distributed model and a lumped model to try and determine when the macroscale model provides an accurate response when compared to the average of the distributed model.

Two distributed model are used in latter sections: one is based on the model described in Famigliett1 and Wood (1992) (referred to as TOPLATS Topgraphic-Land-Atmospheric-Transfer-Scheme) and is an extension of the model described in Famiglietti et al. (1992): these models have been applied to the intensive fleld campaign periods (IFCs) during FIFE of 1987. TOPLATS can include variability in topography, soils, net radiation and vegetation. The first two, topography and soils, leads to variations in soil moisture under the TOPMODEL framework: the latter two lead to variations in potential and actual transpiration. The second model (Wood et al.. 1992) described here has variations in infiltration capacities across a catchment of COM grid square and is referred to as the VIC model. This model has been used in COM climate simulations (see Stamm et al, 1993) and is the model used in this paper to demenstrate the impact of a second order correction term to the lumped model to account for sub-grid heterogeniety.

Derived Distribution of Soll Moisture and Evaporation.

The concept of the representative elementary area leads to a statistical description of the sub-grid variability in water table depths, 
soll moisture, evapotranspiration, and so forth. Models at this scale are referred to as macroscale, distributed models. For TOPLATS, the distribution in the soll-topographic index leads to a distribution in water table depths (see Beven and Kirkby, 1979; Wood et al.. 1990; or Famigliett1 et al.. 1992). From the distribution of water table depths $z$, and the soil characteristic relations which relates the soil matrix head, $\psi$, to soil moisture $\theta$ as a function of soil properties, the statistical distribution for surface soil molsture can be derived. Certain assumptions are usually applied, for example a steady state vertical flow which leads to $\partial \psi / \partial z=1$. Actual evaporation $e_{a}$ (or transpiration from vegetation) depends on the availability of soil moisture ( 1 .e. a soil controlled rate) and the atmospheric demand for moisture; the actual evaporation being the minimum of the two rates. Thus given the atmospheric demand and the the statistical distribution of soll moisture, the distribution of the actual evaporation can be derived. For simple functional forms the mapping of $z \rightarrow \theta \rightarrow e_{a}$ can be done analytically: in any case it can be done through simulation. Figure 2 provides some results using TOPLATS for two conditions: Figure $2 a$ is for quite dry conditions - low water table - for two times during the day. Figure $2 b$ is for the same dirurnal times but for a wetter (but not extremely wet) condition. The parameters for the curves are taken from Famiglietti and Wood (1992) and represent conditions for Kings Creek area of FIFE in Kansas. The figures have been divided into four panels that show the derivation of the bare soll evaporation distribution. Panel (1) in the lower right corner gives the probability distribution for water table depths derived from the soll-topographic index of TOPLATS, and sollwater table depth to surface soil moisture as discussed ewater table depth to surface soll moisture as discussed earlier in this section. These two figures could gewater table depth to surface soll moisture as discussed earlier in this section. These 
two figures could generate a derived probability distribution for surface soil molsture. This is not shown here. The upper left portion of the figure (iii) gives the relationship between surface soll moisture and actual evaporation for the two times during the day. The maximum evaporation rate is the potential rate. which is lower during the early morning and late af ternoon. For portions of the catchment where surface soil mositure is high, the actual evaporation rate is equal to the potential rate. For drier areas, the rate is lower. The resulting probability distribution for the actual evaporation is shown in the lower left portion of the figure. This panel is divided into two. the top giving the distribution for the time related to the lower potential evaporation rate.

Inspection of the derived distributions for the two times and two conditions reveals that for the very dry conditions the distribution for evaporation is narrow and the average water table depth can be used to estimate the average evaporation rate. This is because the soll moisture evaporation function is essentially linear in the range of soil moistures representing the dry conditions. For the wetter condition, the function is non-linear and the range of soil moistures contain areas which are very dry (having low evaporation rates) and wet (having rates at potential.) If the conditions were even wetter, then the distribution of evaporation rates would be at the potential rate. It is at these intermediate conditions where the non-linearities appear to have the greatest impact.

Comparisons between the average bare soll evaporation and that estimated using the average depth to the water table are given in Table 1 for both conditions and the two times. From Figure 2 and Table 1 it is clear that dry conditions during periods of high atmospheric demands result in 
evaporation rates that are biased low. During periods with high soll moisture (or extremely low soil moisture) or during early or late times during the day when the atmospheric demands are low, the bias from using the average water table depth is minimal.

To test the sensitivity due to dry soll conditions and to compare the distributed water-energy balance model (TOPLATS) to a lumped representation (one-dimensional model or a first order model). comparisions were made between the models for 5 days during the October 1987 FIFE intensive field campaign. IFC-4. This period had the driest conditions observed during the 1987 experiment. Figure 3 shows the simulations for October $5-9,1987$. The models were run at a 0.5 hour time step to capture the diurnal cycle in potential evapotranspiration. Three models are compared: a fully distributed model, a macroscale model in which the spatial variability is considered statistically and a lumped one-dimensional model in which parameters and inputs are spatially constant.

The one-dimensional model predicts well the evapotranspiration during the morning and late afternoon when the atmospheric demand is low. but fails to accurately predict this flux during the middle portion of the day when soil and vegetation controls limit the actual evapotranspiration. It is during this period that the sensitivity is high and by ignoring the spatial variability in soil moisture the lumped model serverely underestimates the catchment-scale evapotranspiration. During wet periods, the one-dimensional model may work quite well. This complicates the linkage between a distributed and lumped representation since the appropriateness of the simpler representation varies with the state of the system. 
Linearized, 2nd Order Model for Sub-grid Variability.

While these results imply that distributed models are needed to accurately account for sub-grid variability in soll moisture and the resulting evapotranspiration, such models may be computationally burdensome when incorporated within a COM. An alternative approach would be to develop correction schemes for the of ten used 'lumped' models. Such a scheme should have correction terms that vary with soll moisture conditions.

A lumped representation (or what will also be referred to as a one-dimensional representation) is obtained by using spatially constant values for 'state' variables; in the case of TOPLATS this would be the soll-topographic index and vegetation parameters; In the case of VIC the soil moisture. The effect of representing the distributed model by a lumped model, or equivalently by replacing the spatially variable parameters and inputs by average values, will depend on nonlinearities in the model. Conceptually this can be seen by considering a second order Taylor's series expansion about the mean for the function $y=g[x, \theta]$ where $\theta$ are $f$ ixed parameters and $x$ variable with mean $\mu(x)$ and variance $\sigma(x)$. A first order approximation for $y$ is $\mu_{1}(y) \simeq g[\mu(x), \theta]$. while a second order approximation would be

$$
\mu_{2}(y) \simeq g[\mu(x), \theta]+\frac{1}{2}\left|\frac{d^{2} g}{d x^{2}}\right|_{\mu(x)} \sigma(x)
$$

Differences between $\mu_{1}(y)$ and $\mu_{2}(y)$ depend on the magnt tude of the second term in equation (3) -- the sensitivity term. As an illustrative example, consider the estimation of downslope subsurface flows, $q_{1}$, within TOPLATS with and without considering variability in the local water table $z_{1}$. TOPLATS relates $q_{i}$ to $z_{i}$ by $q_{i}=T_{1} \tan \beta \exp \left(-f z_{i}\right)$. Thus a first order approximation of the mean subsurface flow would be 


$$
\mu_{1}\left(q_{i}\right)=T_{i} \tan \beta \exp (-f \bar{z})
$$

while a second order approximation would be

$$
\mu_{2}\left(q_{1}\right)=T_{i} \tan \beta \exp (-f \bar{z})+\frac{1}{2}\left(T_{1} \tan \beta f\right\}^{2} \exp (-f \bar{z}) \sigma\left(z_{1}\right)
$$

If we scale $\mu_{2}\left(q_{1}\right)$ by $\mu_{1}\left(q_{1}\right)$ and recognize that

$$
\sigma\left(z_{1}\right)=f^{2} \sigma\left(\ln \frac{a T_{e}}{T_{1} \tan \beta}\right)
$$

we obtain

$$
\frac{\mu_{2}\left(q_{i}\right)}{\mu_{1}\left(q_{i}\right)}=1+0.5 \sigma\left(\ln \frac{\alpha T_{e}}{T_{i} \tan \beta}\right)
$$

Analysis of the soil-topographic Index for Kings Creek yields a variance of 3.25. This results in the first order estimate for $q_{i}$ of being biased low by approximately 65\%. Since the subsurface flows and the local water table are related and since the local water table depth effects the surface soil moisture which subsequently determines the soil evaporation and infiltration rates, $1 t^{\prime}$ s clear that the lumped model may very well lead to significant biases in the water balance fluxes.

For the more complex functions used for bare soil evaporation and transpiration, the sensitivities can be determined through simulation. For these functions the sensitivities will change with the state of the catchment (wet or dry). For example Figure 4 gives the vegetation transpiration and soil exfiltration capacities used to model the FIFE data (Famiglietti and Wood, 1992). Notice that at low and high soil moisture values the transpiration capacity function is essentially linear and the sensitivity would be low to soll moisture variations in these ranges. For volumetric moisture contents in the range $0.2-0.3$, the sensitivity of the transpirtaion capacity function is high. As can be seen from Figure 4. sensitivity characteristics for soll exfiltration capacity would be high for soil moisture values greater than about 0.3 . 
moisture, which for any fractional area with capacity 1 greater than $1_{0}$ can be estimated as $\theta=1_{0} \eta / 1$. where $\eta$ is the soil porosity. Using the results for a Beta distribution between $\left[1_{0}, 1_{m}\right]$ results in a mean and variance for 1 conditional upon $1>1$ of

$$
\begin{aligned}
& \bar{i}=1_{0}+\left(i_{m}-i_{0}\right) /(1+B) \\
& \operatorname{Var}(i)=\left(i_{m}-i_{0}\right)^{2} \frac{B}{(1+B)^{2}(2+B)}
\end{aligned}
$$

A second order mean soil moisture can be estimated using (7) as

$$
\begin{aligned}
& \bar{\theta}=\frac{i_{0} \eta}{\bar{i}}+\frac{i_{o} \eta}{\bar{i} 3} \operatorname{Var}(1) \\
& \operatorname{Var}(\theta)=\frac{\left(i_{0} \eta\right)^{2}}{\bar{i} 4} \operatorname{Var}(i)
\end{aligned}
$$

To estimate bare soil evaporation we can use a Philip's form of the exfiltration capacity (Eagleson, 1978) which is of the form $E=0.5 \mathrm{~s}_{e} \mathrm{t}^{-1 / 2}$. where $S_{e}$ is a desorptivity term that can be written in the form $s_{e}=K\left(\theta-\theta_{r}\right)^{C / 2}$. Here $K$ and $C$ are parameters which depends on soil characteristics. Using the mean and variance of $\theta$ will yield a second order model for the mean soll evaporation rate whose sensitivity will depend on the variance of $\theta$ and the sensitivity term for the evaporation function. After some simple algebra, the sensitivity term $d^{2} E / d \theta^{2}$ can be written as

$$
\frac{d^{2} E}{d \theta^{2}}=\left(\frac{C}{2}\right)\left(\frac{C}{2}-1\right) \frac{E}{\left(\bar{\theta}-\theta_{r}\right)^{2}}
$$

where $E$ is evaluated at $\bar{\theta}$, and $\theta_{r}$ is the residual soil moisture.

To test the algorithm and compare it with the distributed VIC model, simulations were run varying the initial soll water capacity $\left(W_{0}\right)$ and 
for different shape parameters for the distribution of infiltration capacities. (see equation 8 ). The simulations used potential evaporation data from IFC-4 of FIFE'87. The following initial parameters were used: a maximum infiltration capacity, $i_{m}=30.5 \mathrm{~cm}$ and a shape parameter of $B=0.3$. Using an intial wetness corresponding to $i_{0}=10 \mathrm{~cm}$ yield the results shown in Figure 7. The solid line represents the distributed VIC model in which evaporation is estimated using 100 slices of the soil moisture distribution. The dotted line is the solution using the average value of soll moisture for where $i>i_{0}$ (i.e. a 1st order linear model) and the dashed line is the 1st order model plus the correction term (i.e. the 2nd order, linearized model.) For this case, the correction term is about $50 \%$ of the estimate using just the average soil moisture. If the conditions are wetter than Figure 7. 1.e. have $1_{0}=15 \mathrm{~cm}$, then we get the results shown in Figure 8 . Here the lumped model does very well. If conditions drier than Figure 7 prevail, $1 . e .1_{0}=5$ $\mathrm{cm}$ (which is very dry) then the linearized model does very poorly: as shown in Figure 9.

The results do depend on the value of $B$, the shape parameter. For example having $B=1.3$ and $i_{0}=10 \mathrm{~cm}$ (the conditions of Figure 7 ) resulted in much better performance of the correction algorithm as can be seen in Figure 10. As shown in Stam et al. (1993), the distribution of B ranges globally from about 0.3 to 2.5 suggesting that the applicability of such a correction algorithm may be widespread. Furthermore, 1 t can be determined before hand where the algor 1 thm should work, and under what soil moisture conditions. This suggests that for those COM grid squares with sufficient moisture or favorable infiltration capacity shape parameters, the simple 2nd order algorithm can be implemented. For condition too dry, the distributed model can be run for those particular time steps. This approach would lead to the most efficient and accurate computational effort. 


\section{Conclusions}

The effect of subgrid variability in soil moisture on evaporation has been investigated with the aim of resolving whether effective (or average) values for soil molsture can replace the distribution found within a catchment or GCM grid square. It appears that there is a critical range of intermediate values for which the subgrid variability has a significant impact of grid total evaporation (and transpiration). This arises from the non-linearlty between soll molsture and evaporation within this critical range, and the essentially linear behavoiour outside this range.

This lead to an initial attempt in developing a 2nd order, linearized, model for evaporation that could be incorporated with GCMs. Initial performance of this algorithm is encouraging with the correction term representing about $50 \%$ of the evaporation predicted based on only using the average soil moisture value. For extremely dry conditions the linearized model still under estimates evaporation which may result in using the fully distributed model in these conditions.

\section{Acknow ledgements}

I would like to thank J. Famiglietti and V. Lakshmi with their help in running some of the examples used in this paper, and D. Thongs and J. Stamm with some of the graphics. The research was supported in part from NASA grants NAG-5-899 and NAGW-1392; this research support is gratefully acknowledged. 


\section{References}

Abbott, M.B., J.C. Bathurst, J.A. Cunge, P.E. O'Connell, and J. Rasmussen. "An Introduction to the European Hydrological System-Systeme Hydrologique Europeen SHE, 1. History and Philosophy of a Physically-Based, Distributed Modelling System". Journal of Hydrology, 87, 45-59, $1986 a$.

Abbott, M.B., J.C. Bathurst, J.A. Cunge, P.E. O'Connell, and J. -Rasmussen. "An Introduction to the European Hydrological System-Systeme Hydrologique European SHE, 2, Structure of a Physically-Based, Distributed Modelling System", Journal of Hydrology, 87, 61-77, 1986b.

Beven, K. and M. J. Kirkby. "A Physically Based, Varlable Contributing Area Model of Basin Hydrology, Hydrol. Sci. Bull., 24(1), 43-69, 1979.

Binley, A.M., J. Elgy and K.J. Beven. "A Physically-Based Model of Heterogeneous Hillslopes". Water Resources Research , 25, 1219-1226, 1989.

Charney, J.,W. Quirk. S. Chow and J. Kornfleld. "A Comparative Study of the Effects of Albedo Change on Drought in Semi-Arid Regions". Journal of the A tmospheric Sciences, 34, 1366-1385, 1977.

Eagleson, P.S., "Climate, Soll and Vegetation". Water Resources Research. 14(5), 705-776, October, 1978. 
Famiglietti, J.S., and Eric F. Wood, "Aggregation and Scaling of Spatially-Variable Hydrological Processes, 1. A Local Model of Water and Energy Balance; 2, A Catchment-Scale Model of Water and Energy Balance; 3, A Nacroscale Model of Water and Energy Balance". submitted to Water Resources Research, October. 1992.

Famigliett1. J.S. and Eric F. Wood, "Aggregation and Scaling of Spatially-Variable Hydrological Processes, 4, Effects of Spatial Variability and Scale on Areal-Average Evapotranspiration". submitted to Water Resources Research, January, 1993.

Famigliett1, J.S., Eric F. Wood, M. Sivapalan and D.J. Thongs, "A Catchment Scale Water Balance Model for FIFE". Journal of Geophysical Research, November, $1992 a$.

Moore, I.D., E. M. O'Laughlin and G.J. Burch. "A Contour-Based Topographic Model for Hydrological and Ecological Applications", Earth Surf. Processes Landf orms, 13, 305-320, 1988.

Paniconi, C. and Eric F. Wood, "A Detailed Model for Simulation of Catchment Scale Subsurface Hydrologic Processes". Water Resources Research, in press (1992) .

Sellers, P.J., F.G. Hall, G. Asrar, D.E. Strebel and R.E. Murphy. "The First ISLSCP Field Experiment (FIFE)". Bulletin of the American Meteorological Society, 69, 22-27, 1988. 
Sellers, P. J., M. Heiser and F. G. Hall "Relations Between Surface

Conductance and Spectral Vegetation Indices and Intermediate $\left(100 \mathrm{~m}^{2}\right.$ to 15 $\mathrm{km}^{2}$ ) Length Scales". J. Geophys. Res.. 97(D17), 19033-19059, November 30. 1992.

Shukla, J. and Y. Mintz. "The Inf luence of Land-Surface Evapotranspiration on Earth's Climate". Science, 215, 1498-1501, 1982.

Stamm. J., E. F. Wood, and D. Lettenmaier "Sensitivity of a GCM Simulation of Global Climate to the Representation of Land Surface Hydrology", submitted J. Climate (1992).

Sud, Y. C. P. Sellers, M. D. Chow, G. K. Walker and W. E. Smith "Influence of Biosphere on the Global Circulation and Hydrologic Cycle - A GCM Simulation Experiment", Agricultural and Forestry Meteorology, 52, 133-188. 1990.

Walker, J.M. and P.R. Rowntree, "The Effect of Soll Moisture on Circulation and Rainfall in a Tropical Model". Quart. J.R. Meteor. Soc., 103, 29-46.

Wood, Eric F. and V. Lakshmi. "Scaling Water and Energy Fluxes in Climate Systems: Three Land-Atmospheric Modeling Experiments". J. of Climate. 6(5). 839-857. 1993. 
Wood, Eric F., K. Beven, M. Sivapalan and L. Band, "Effects of Spatial Variability and Scale with Implication to Hydrologic Modeling". Journal of Hydrology, 102, 29-47, 1988.

Wood, Eric F., M. Sivapalan and K.J. Beven. "Similarity and Scale in Catchment Storm Response". Reviews in Geophysics, 28(1), 1-18, February 1990.

Wood, Eric F., D.-S. Lin, M. Mancini, D. Thongs, P.A. Troch, T.J. Jackson and E.T. Engman, "Intercomparisons Between Passive and Active Microwave Remote Sensing, and Hydrological Modeling for Soll Moisture". Symposium A.3, Progress in Scientific Hydrology and Water Resource Management using Remote Sensing. Proceedings of the 29th Plannery Meeting of the Committee on World Space Research, (OOSPAR), Washington, D.C.August 28-September 5, 1992.

Wood. Eric F., D.P. Lettenmaier and V.G. Zartarian, "A Land Surface Hydrology Parameterization with Sub-Grid Variability for General Circulation Models". Journal of Geophysical Research, 97/D3, 2717 - 2728, February 28, 1992.

World Climate Research Programe "The Scientific Plan for the GEWEX Continental-Scale International Project". WCRP-67 MO/TD-No. 461, Geneva, Switzer lamnd, February 1992, 65pp. 
Table 1. Average Evaporation Rates

\begin{tabular}{|c|c|c|c|c|}
\hline \multirow[b]{2}{*}{$\begin{array}{c}\text { Soll } \\
\text { Condition }\end{array}$} & \multicolumn{2}{|c|}{$\begin{array}{l}\text { Average based on the } \\
\text { Variable Evaporation }\end{array}$} & \multicolumn{2}{|c|}{$\begin{array}{c}\text { Average based on using } \\
\text { average } \bar{z}\end{array}$} \\
\hline & $\begin{array}{l}\text { Potential } \\
\text { Low }\end{array}$ & $\begin{array}{l}\text { Evaporation }(\mathrm{mm} / \mathrm{hr}) \\
\text { High }\end{array}$ & $\begin{array}{c}\text { Potential } \\
\text { Low }\end{array}$ & $\begin{array}{c}\text { Evaporation }(\mathrm{mm} / \mathrm{hr}) \\
\text { High }\end{array}$ \\
\hline $\begin{array}{l}\text { Dry } \\
\text { Wet }\end{array}$ & $\begin{array}{l}0.051 \\
0.11\end{array}$ & $\begin{array}{l}0.037 \\
0.088\end{array}$ & $\begin{array}{l}0.054 \\
0.12\end{array}$ & $\begin{array}{l}0.046 \\
0.097\end{array}$ \\
\hline
\end{tabular}


Figure 4: Vegetation transpiration capacity and bare soll evaporation capacities as functions of soil moisture (from Famiglietti and Wood, 1992).

Figure 5: (a) Actual soil evaporation for five different times during a day, notice that the actual level is the minimum of the capacity (figure 4) and the potential. (b) The evaporation sensitivity term $\partial^{2} E_{s} / \partial \theta^{2}$ for the same times as in (5a).

Figure 6: The vegetation transpiration sensitivity term $\partial^{2} \mathrm{~T}_{\mathrm{v}} / \partial \theta^{2}$.

Figure 7: Comparisons of model derived latent heat estimates using the distributed VIC model for medium dry conditions, a 1st order linear model and a 2nd order linear model. Pamameters for the simulation are given in the text.

Figure 8: Comparisons of model derived latent heat estimates using the distributed VIC model for wet conditions, a 1st order linear model and a 2nd order linear model. Pamameters for the simulation are given in the text.

Figure 9: Comparisons of model derived latent heat estimates using the distributed VIC model for very dry conditions, a 1st order linear model and a 2nd order linear model. Pamameters for the simulation are given in the text.

Figure 10: Comparisons of model derived latent heat estimates using the distributed VIC model for the moisture conditions used in figure 7 and a modified soil capacity shape parameter. Also shown are a 1st order linear model and a 2nd order linear model. Pamameters for the simulation are given in the text. 


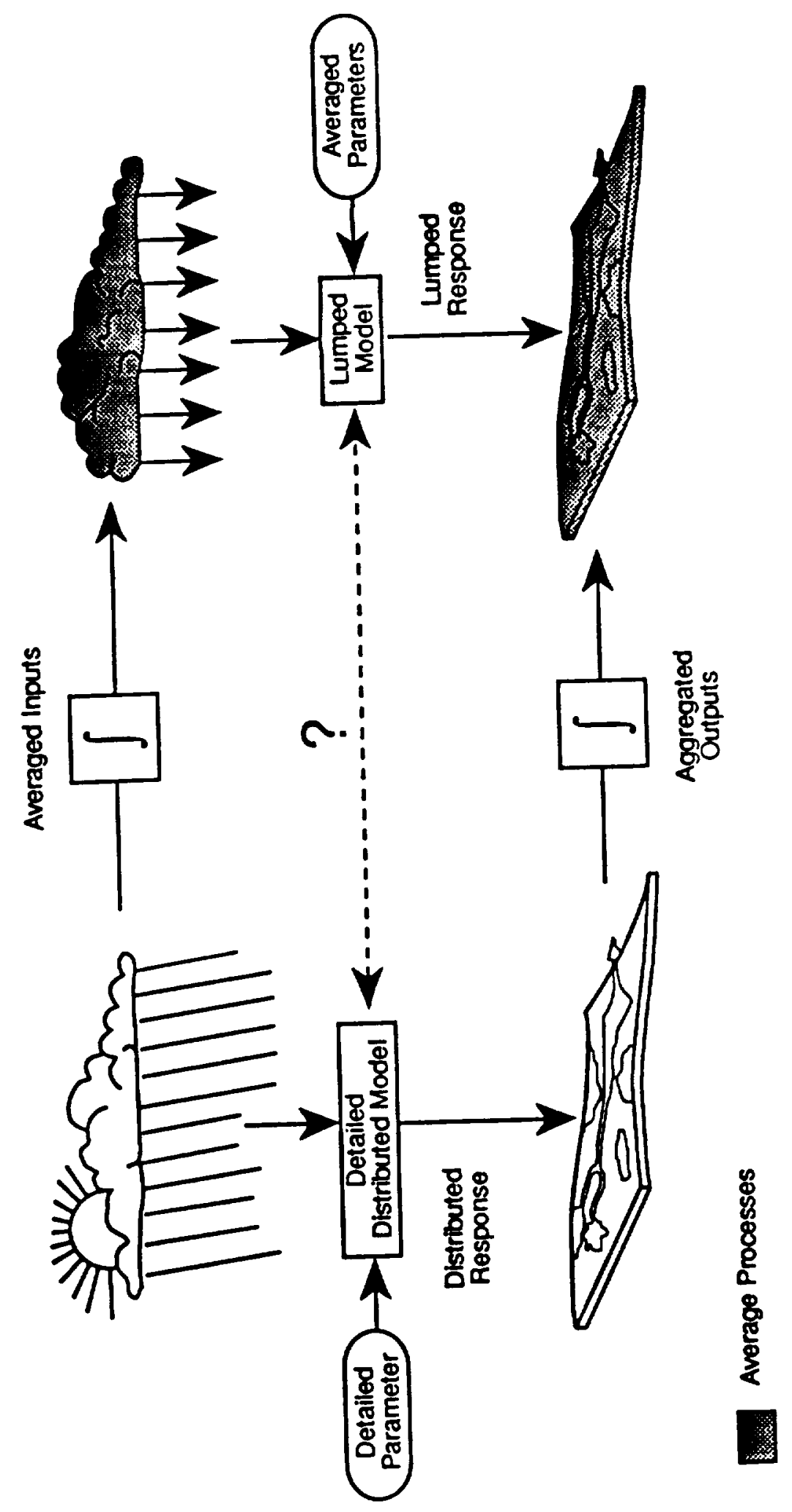



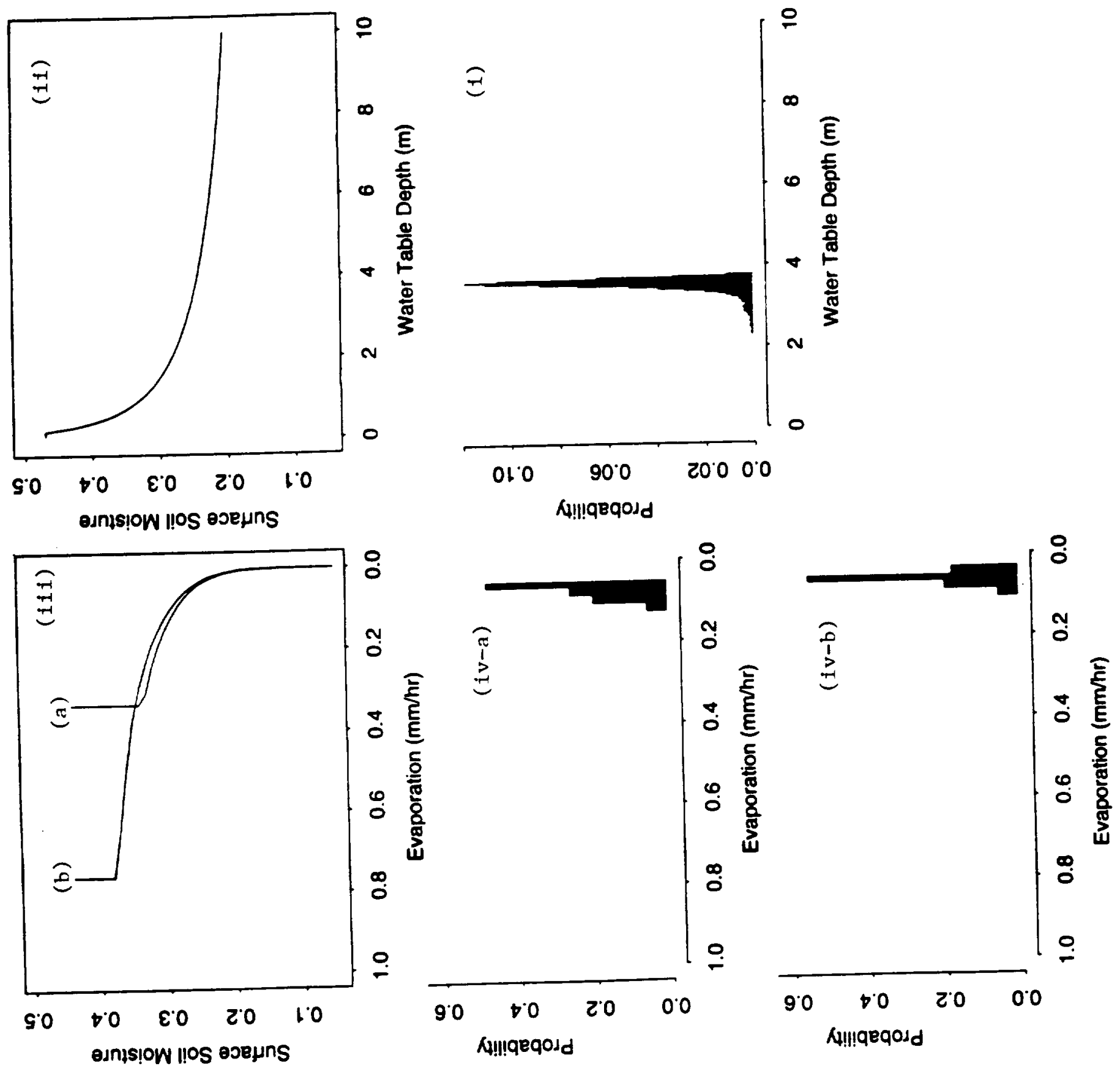

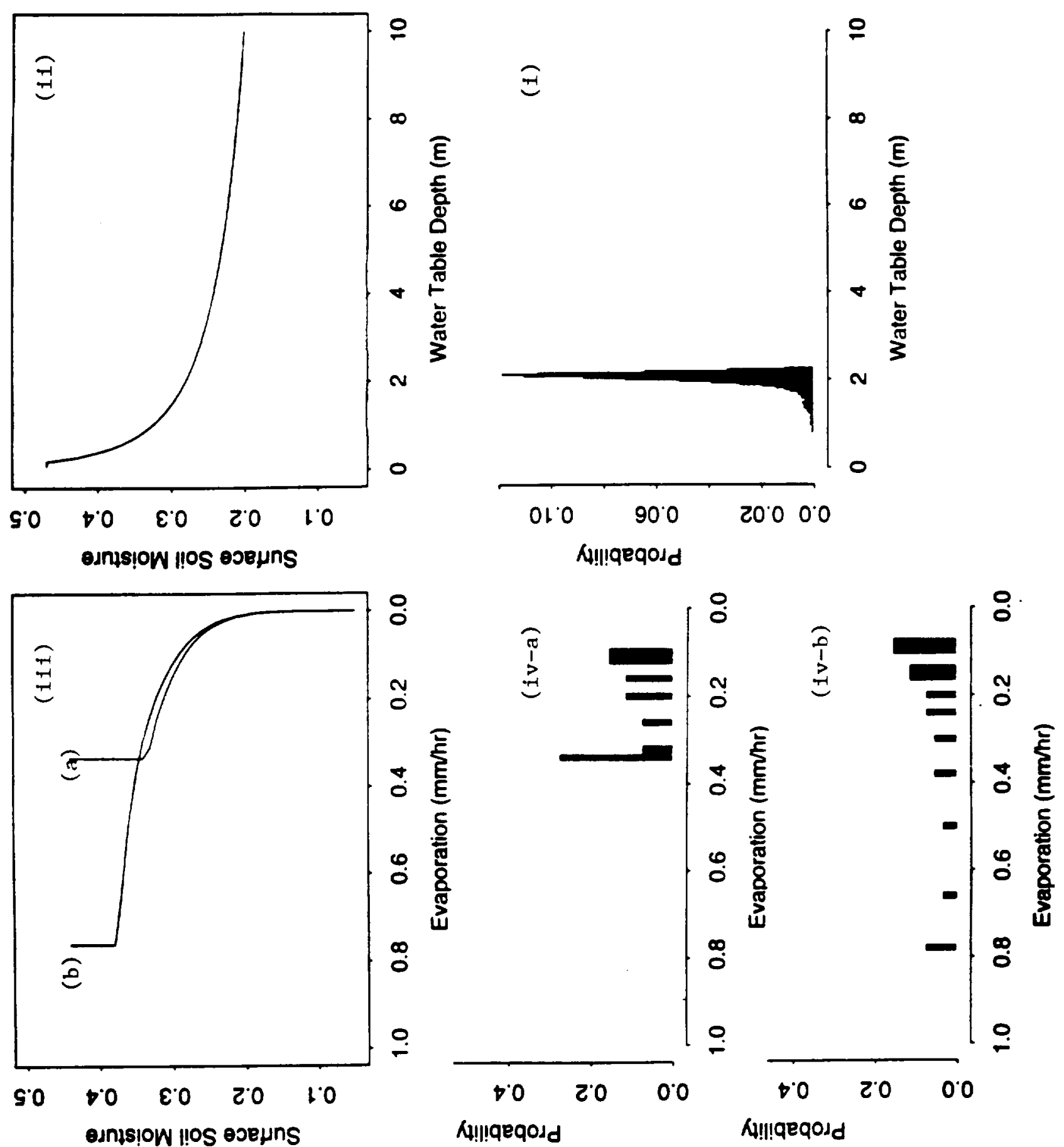


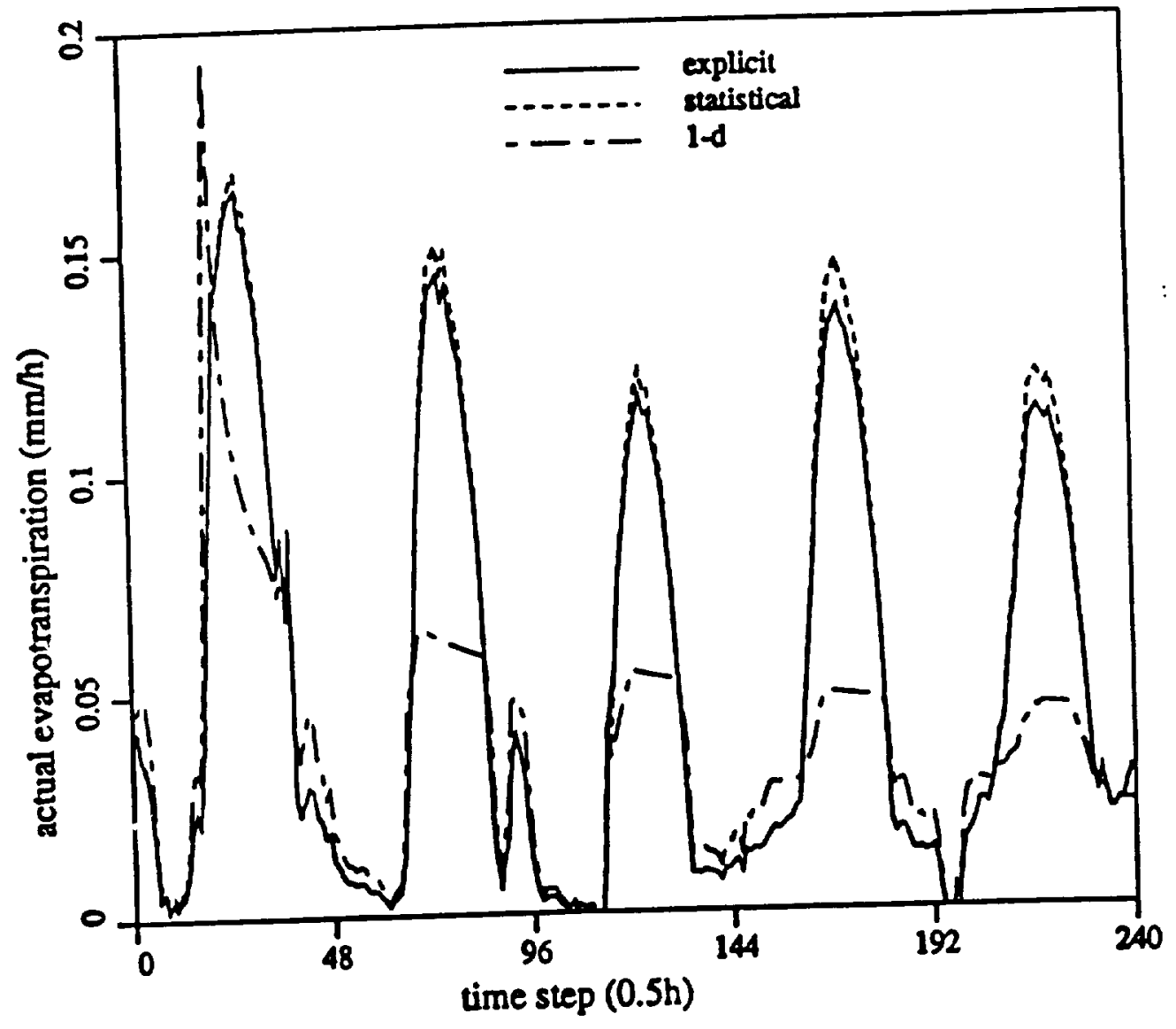




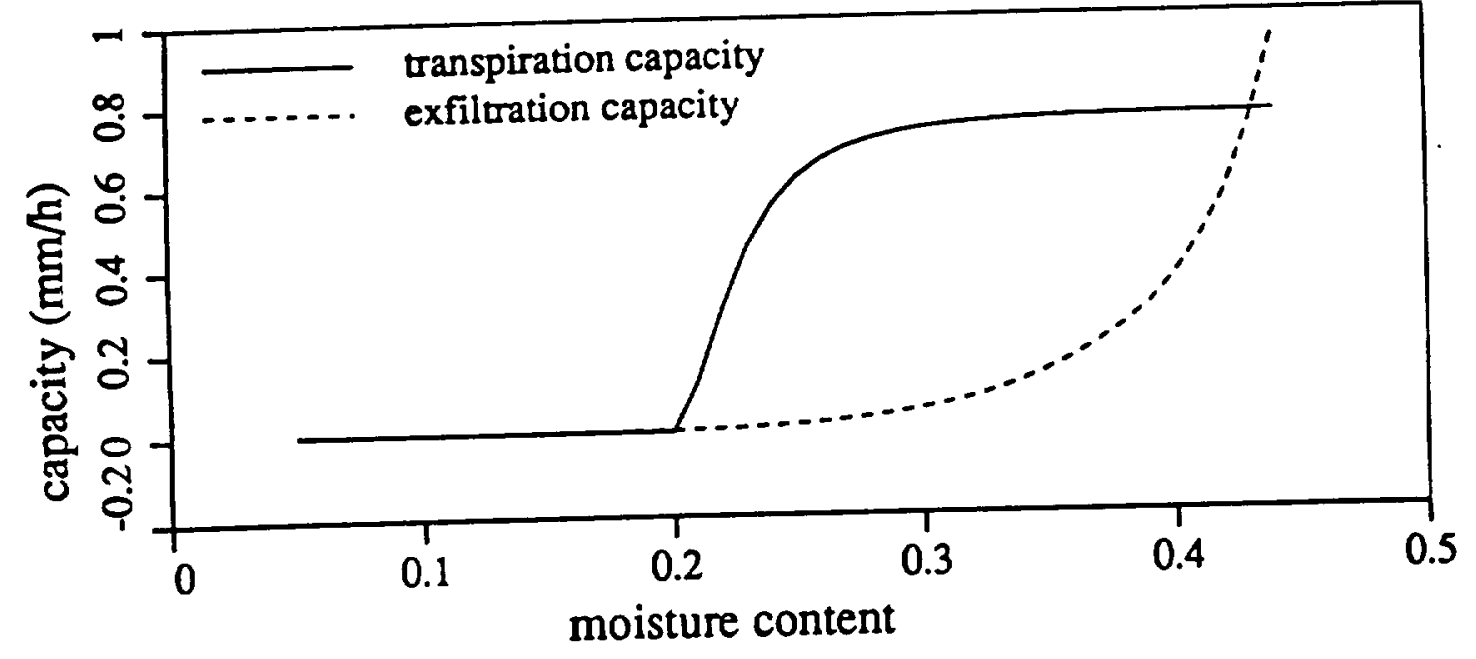

F. 4 
Bare Soil
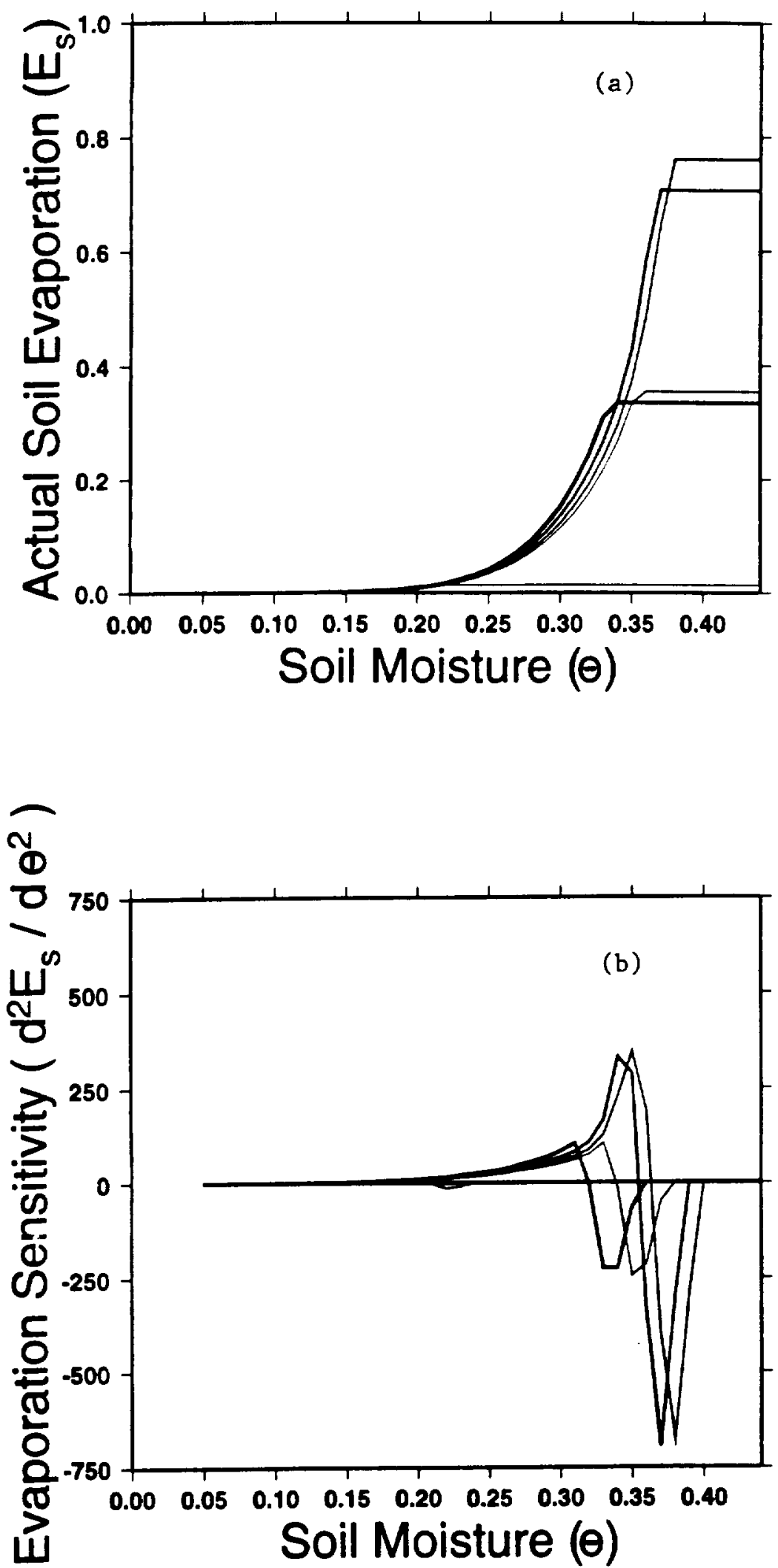

Fic 


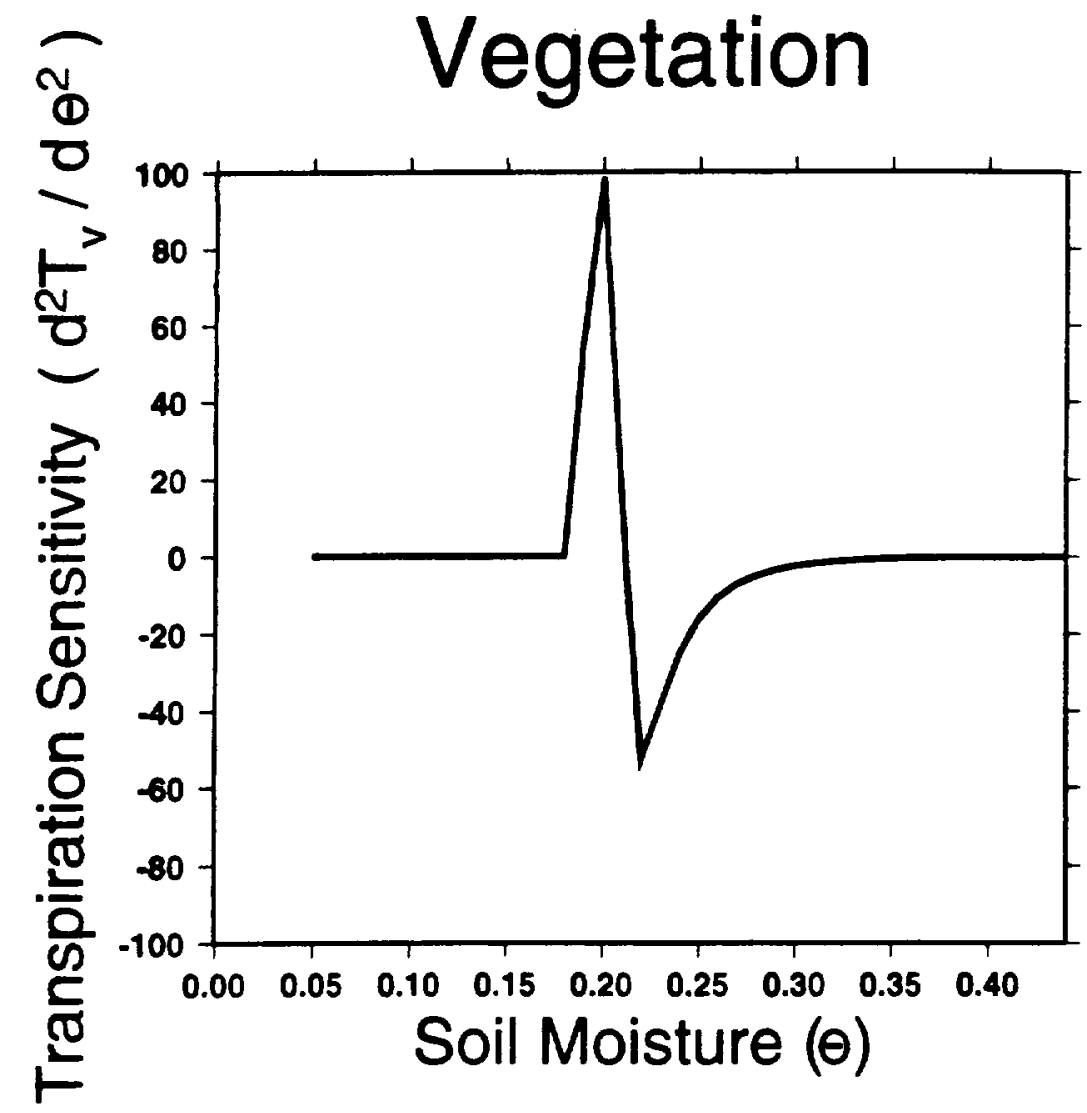




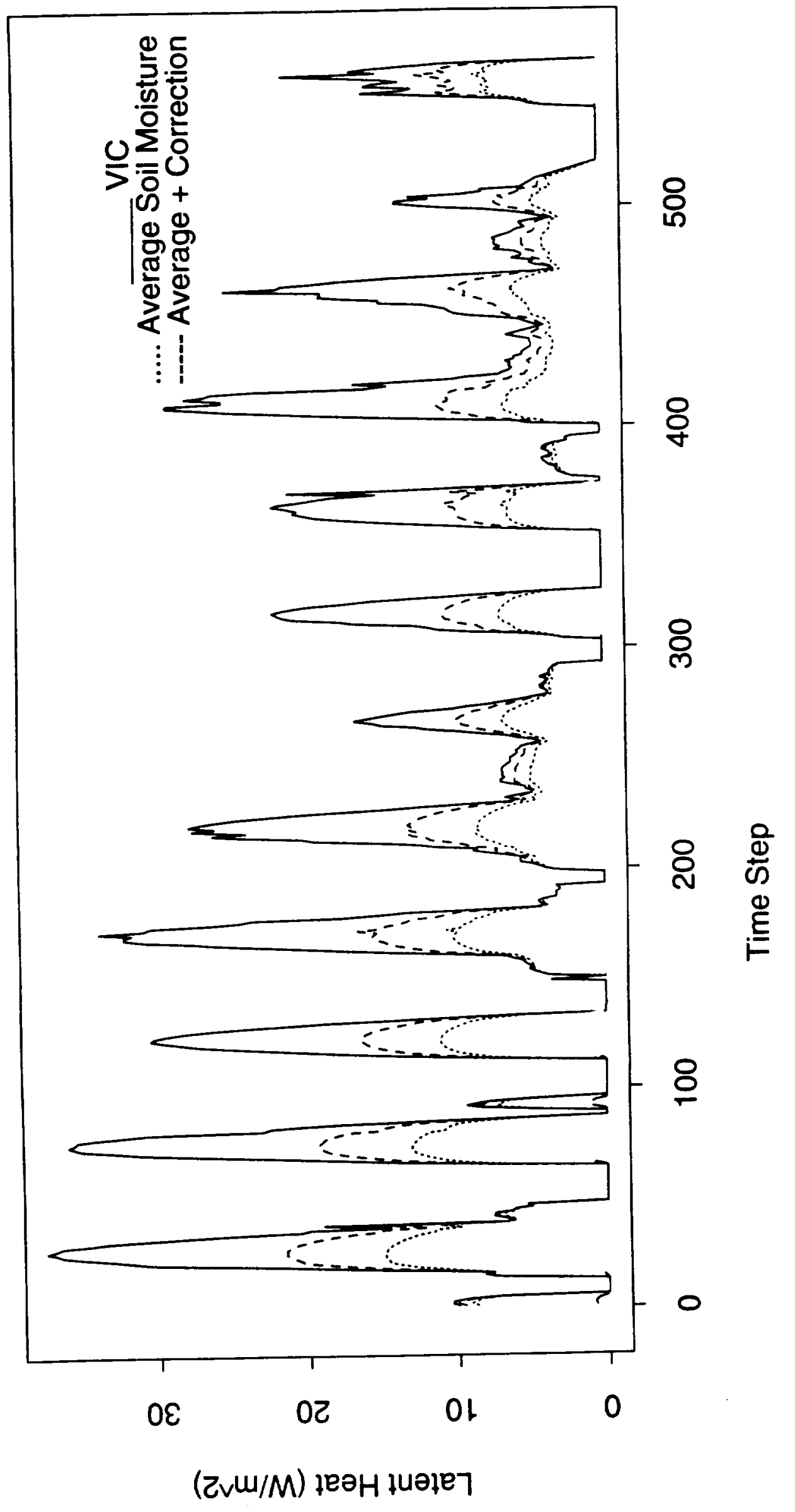




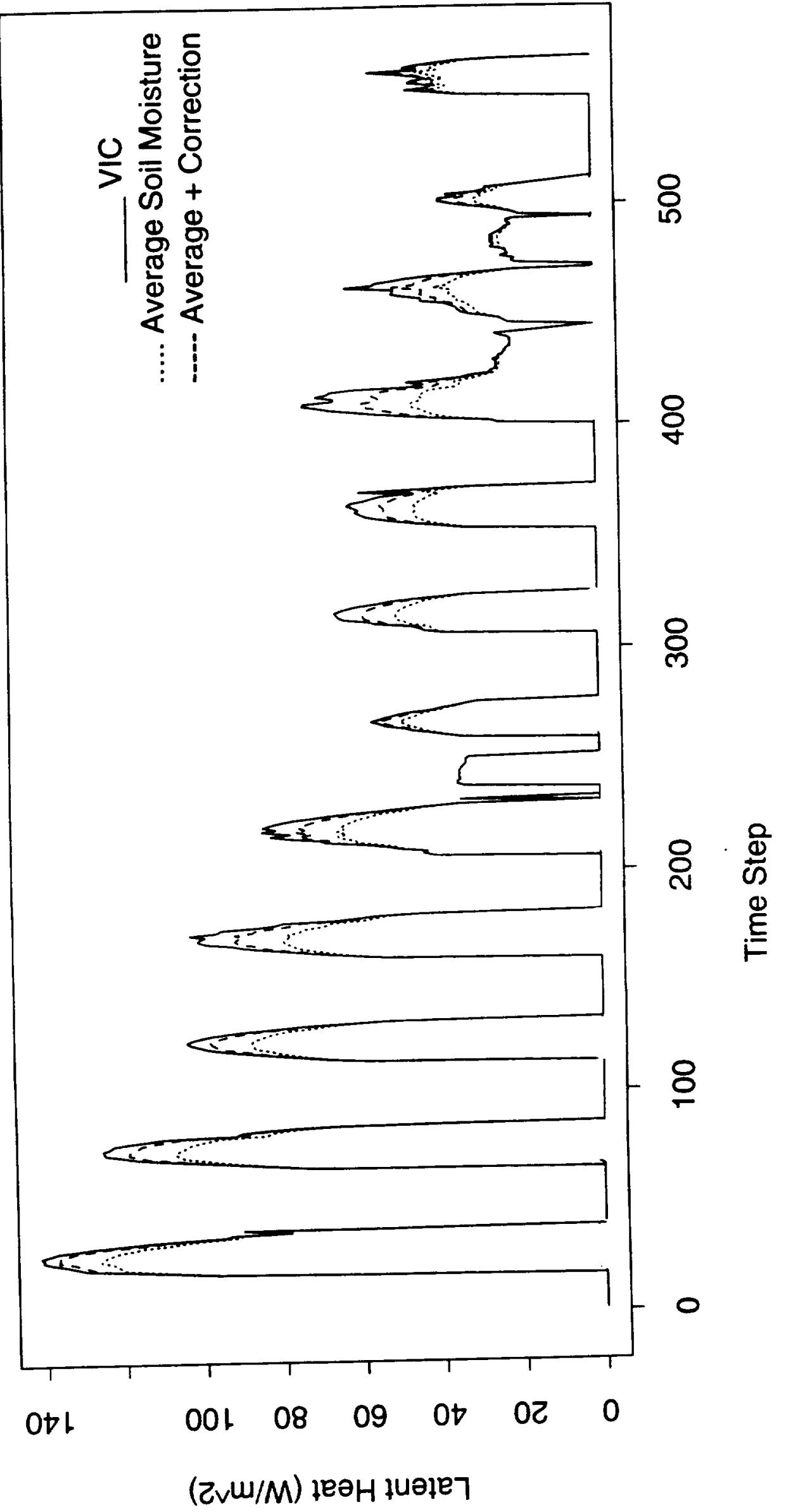




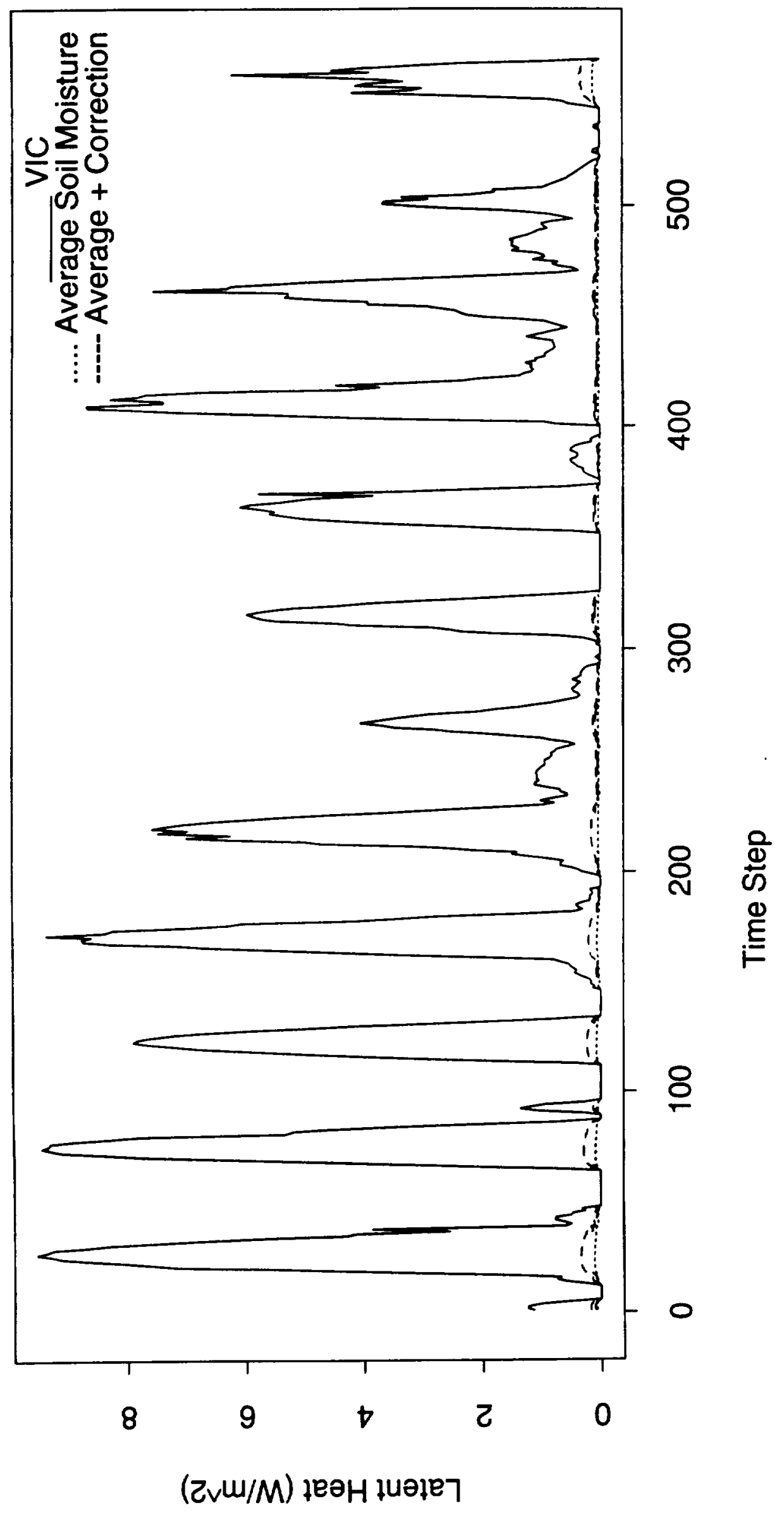




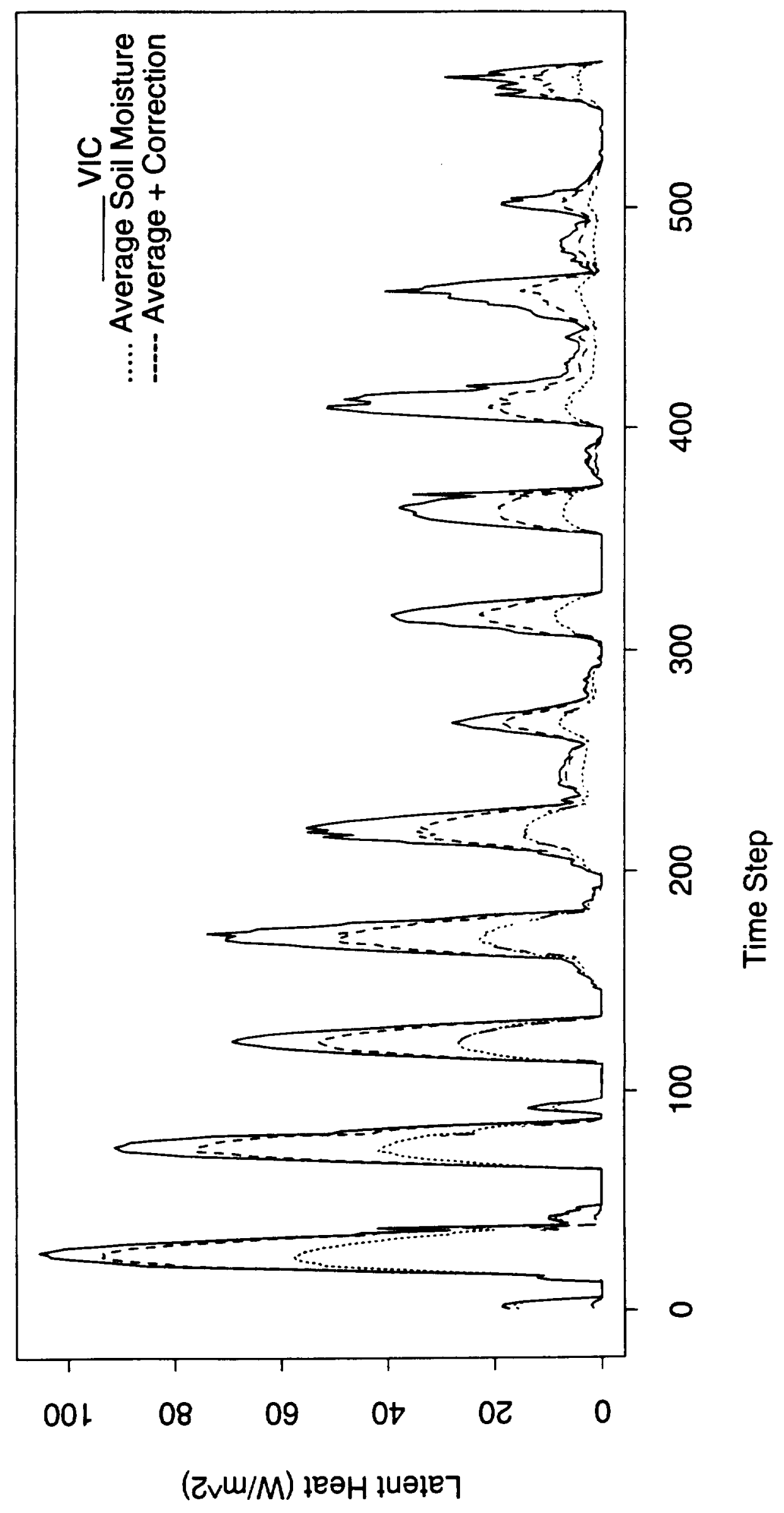


. 